\title{
Dental Paleopathology of the Ray Site (12W6), Indiana
}

\author{
Tammy R. Greene \\ Department of Anthropology, University of Alaska, Fairbanks AK 99775
}

\begin{abstract}
The Ray site (1 2W6), in southern Indiana, contains several secondary burials, two of which have been dated to the Mississippian period (A.D. 1050-A.D. 1450). Three burial styles were noted: (1) burials lined with stone slabs and containing Mississippian pottery, (2) burials lined with stone slabs without Mississippian pottery, and (3) burials not lined with stone slabs and without Mississippian pottery. The purpose of this study was to determine the biological homogeneity of this poorly preserved skeletal assemblage via an analysis of dental pathological conditions, the frequency and expression of which are known to associate with distinct dietary and/or settlement patterns. Conditions studied include the frequency of hypoplastic defects and carious lesions, the type of hypoplastic defects, the earliest age of onset of hypoplastic defects, and the location of carious lesions. A total of 437 teeth were scored for hypoplastic defects and 433 were scored for carious lesions. No significant difference in dental pathologies was found between burial styles. Therefore, despite considerable burial heterogeneity, dental pathological conditions suggest that individuals from all burials consumed an equally cariogenic diet and underwent similar childhood stresses. It is most likely that all burials are from the same temporal and social group and that the different burial styles represent different stages in the processing of the remains of individuals from a high social status Mississippian mortuary.
\end{abstract}

Many researchers have determined that the expression of certain dental pathological conditions is not randomly distributed through time among prehistoric humans from the American Midwest (e.g., Goodman et al., 1984b; Sciulli and Schneider, 1986; Larsen et al., 1991; Schmidt, 1998; Schmidt and Williamson, 1998). Rather, these conditions tend to correlate with a population's diet, density, and degree of sedentism. Populations that consumed domesticates such as maize and lived in dense settlements tended to suffer more profoundly from dental caries and disruptions in tooth formation than those who consumed fewer or no domesticates and lived in small groups (Powell, 1985). Researchers have verified associations between diet and dental disease throughout the world (e.g., Enwonwu, 1981; Walker and Erlandson, 1986; Kelly et al., 1991; Buikstra, 1992).

Archeology textbooks that discuss the transition to agriculture tend to ignore the biological record in favor of the more easily defined and recognized social, cultural, and technological transformations (Larsen, 1995). However, biological changes are an essential concomitant of lifeway transitions. These biological changes reflect non-specific indicators of diet, health, and workload, and sometimes, more specific indicators such as particular diseases or individual activities. Segments of a single population may be affected differentially by adopting agriculture. Likewise, populations may experience idiosyncratic biological changes, depending upon their region, the agricultural resource being

Editor's note: Ms. Greene's paper was awarded Honorable Mention for 2001 in the Albert A. Dahlberg student research competition sponsored by the Dental Anthropology Association. adopted, and preceding subsistence strategies. In other words, alterations that accompanied agriculture may have been highly localized (Larsen, 1995).

Recent preliminary studies of the Ray site, which has been considered by archeologists to be a singlecomponent cemetery, have shown several contradictions to the general rules of small Mississippian mortuary sites. Differences in the orientation of the graves, positioning of the remains, and inclusion of artifacts may suggest heterogeneity that exceeds typical small Mississippian cemeteries. The purpose of this study was to determine whether the skeletal sample is also biologically heterogeneous. Since the frequency and expression of dental pathological conditions are known to associate with distinct dietary or settlement patterns, heterogeneity of these conditions within the assemblage would suggest that most heterogeneity is due to representation of more than one population or temporal period. For example primary and secondary interments, which represent different stages in the processing of remains may be seen at many high social status Mississippian mortuaries, and could be represented by different burial styles. Hypoplastic enamel defects and carious lesions are analyzed to determine whether these conditions vary systematically by grave style or the inclusion of artifacts, thus exposing culturally and/or temporally distinct subgroups.

\section{Hypoplasia}

Hypoplastic enamel defects include various malformations on the crown surface from furrows to pits that represent episodic disruption of enamel matrix secretion during growth (Goodman and Armelagos, 1985; Goodman and Rose, 1991). The surface profile of the tooth is altered due to a convergence of the striae of 
Retzius as they approach the enamel surface as well as abnormal prism structure along the defect. Because of the appositional nature of enamel, the area of the defect is often overlapped by normal enamel, resulting in locally thin but not necessarily absent enamel (Pindborg, 1970; Goodman and Rose, 1990).

Many childhood stressors have been linked to hypoplastic enamel defect formation, including vitamin $\mathrm{A}$ and D deficiencies, fever, gastroenteritis (Goodman et al, 1984a) under- and over-nutrition, and hormonal changes (Goodman and Armelagos, 1985). In fact, most stressors, if severe enough, result in disruptions of enamel development (Goodman and Rose, 1991), although it is likely that the combination of several stressors is necessary to form a defect. While it may be impossible to distinguish the exact cause of hypoplastic enamel defects, their presence or absence provides insight into the metabolic state of an individual at the time of their dental matrix formation (Goodman and Rose, 1990). Teeth that develop while host resistance is low and environmental insults are high are more likely to have hypoplastic defects (Goodman and Armelagos, 1985). The presence of a hypoplastic defect on the tooth suggests that the health of the child was sufficient to overcome those environmental insults.

Hypoplastic enamel defects are found in every Native American group and are more frequent in agricultural groups (Sciulli, 1978; Goodman and Rose, 1990). Sciulli (1978) presents frequencies of hypoplastic enamel defects for several groups from various time periods: a pre-agricultural group from Ohio showed a frequency of 33\%; mixed economy groups showed an average of $28.5 \%$; agricultural groups showed frequencies from $43 \%$ to $70 \%$.

Age at which the hypoplastic defect occurs has also been shown to change through time. Goodman et al. (1984a) examined two successive prehistoric populations from Dickson Mounds (A.D. 950-1150, mixed economy; and A.D. 1150-1300, agriculture) in Illinois. The former group had a peak frequency between 3.0 and 3.5 years. The latter had a peak frequency between 2.5 and 3.0 years (Goodman et al., 1984a).

\section{Carious Lesions}

Carious lesions are among the most frequently reported pathological conditions of the dentition. The lesions are areas of the teeth that have been destroyed by acids produced in dental plaque by bacterial fermentation (Heloe and Haugejorden, 1981). Carious lesions develop under dental plaques, which are dense bacterial masses (Gibbons and Van Houte, 1975). Streptococci and gram-positive filamentous bacteria are most often associated carious lesions (Gibbons and Van Houte, 1975). The bacteria feed on the carbohydrates in the mouth producing waste in the form of lactic acid (Hillson, 1979).

The relationship between diet and carious lesions has been well-established (Jacobsen and Hansen, 1974; Pedersen, 1938; Mayhall, 1970; Bang and Kristoffersen, 1972). It is accepted that increased dependency on foods such as sugars and carbohydrates leads to a higher incidence of carious lesions. Increases in carious lesion rates accompanying a dietary shift to greater carbohydrate consumption have been noted in Greenland (Jacobsen and Hansen, 1974; Pedersen, 1938), Canada (Mayhall, 1970), Alaska (Bang and Kristoffersen, 1972), Africa (Enwonwu, 1981), Asia (Infirri and Barmes, 1979), and Europe (Corbett and Moore, 1976). The location of carious lesions along the tooth row has also been shown to change with subsistence strategies. Lesions tend to occur almost exclusively at the CEJ (cemento-enamel junction) in pre-agricultural populations. Foods commonly become lodged around the gum-line. Populations that regularly consume refined carbohydrates more often develop carious lesions on the crowns. Carbohydrates are sticky and are easily trapped in the grooves in the enamel surface (Smith, 1986).

Frequencies of carious lesions differ among males and females in many geographic locations (Lukacs, 1996). However, Mississippian sites in the Midwest do not tend to show differences between the sexes (Smith, 1986). Thus foods consumed by males and females are equally cariogenic. The relationship of carious lesion frequency with age is somewhat less established. The Angel site, located near and believed to be contemporaneous with the Ray site, shows a decrease in carious lesion frequency with age (Schmidt, 1998). This decrease may be related to tooth wear. As a tooth wears, there are fewer grooves in which sticky foods may become lodged, thereby reducing the risk of bacterial decay.

\section{MATERIALS}

The current study examined mortuary homogeneity in a small late prehistoric mortuary. The Ray site (1 2W6) overlooks Little Pigeon Creek near its entry into the Ohio River in Warrick County, Indiana. The Ray site is six miles east of the Angel site $(12 \mathrm{Vgl})$ and one mile north of the Yankeetown site (12W1). Black (n.d.) first characterized the Ray site as Yankeetown (A.D. 750 - 1050). In a reevaluation, Ball (1993) suggests that the Ray site represents an early Angel phase (Mississippian period, A.D. 1050-1450) mortuary placed over an earlier Yankeetown domestic occupation site. Placement of the Ray site within the Angel phase and its relationship to the Angel site are not entirely clear (Ball, 1993).

The excavations produced eleven prehistoric burials and several intrusive Euro-American burials. The EuroAmerican burials were not examined. Three distinct burial classifications can be seen. These include (1) burials with Mississippian pottery and stone slabs, (2) burials with stone slabs without Mississippian pottery, and (3) burials with no Mississippian pottery 
TABLE 1. Description of burials ${ }^{1}$

\begin{tabular}{clll}
\hline Burial & MNI & \multicolumn{1}{c}{ Stone Slab? } & Mississippian Pottery? \\
\hline 1 & Unknown & Shale & Sandstone pipe \\
2 & Unknown & None & No \\
3 & 10 & Shale, Horizontal? & Yes \\
4 & 17 & None & No \\
$5 \mathrm{a}$ & 1 & Shale, Vertical & No \\
$5 \mathrm{~b}$ & 8 & Sandstone, Vertical & No \\
6 & 1 & None & No \\
7 & 2 & None & Unknown \\
8 & 1 & None & No \\
9 & Unknown & None & No \\
10 & 6 & None & No \\
11 & 1 & Shale, Horizontal & No \\
12 & 5 & Shale \& Sandstone, Vertical & Yes \\
13 & 2 & None & No \\
\hline
\end{tabular}

${ }^{1} \mathrm{MNI}$ (minimum number of individuals) was determined through dental remains. The numbers given in the field notes were based on rough skull counts and therefore may differ from dental counts.

or stone slabs. There are no burials at the Ray site with Mississippian pottery that do not have stone slabs. The association of burials 7,8 , and 9 with any burial style is unclear (Ball, 1993), thus these burials are not considered in the present study. Burials 1 and 2 were not collected (Black, n.d.). See table 1 for a description of the burials.

\section{METHODS}

All Ray site teeth were first cleaned with a weak ethyl acetate solution to remove the white paint that had been placed on the crowns for labeling in the 1950s. Teeth still housed in bony sockets had been covered with the preservative Aluvar in the field before removal of the soil. Removing the preservative with the ethyl acetate caused minimal damage to the crowns; however, some required reconstruction. Teeth that appeared cracked under the preservative were not cleaned and were not included in the study. An inventory of all complete and fragmented teeth from the Ray site was taken in order to establish a minimum number of individuals (MNI). Because of the low occurrence of primary teeth in this sample, they cannot be studied separately and were therefore not examined. Table 2 summarizes the inventory of permanent teeth that were included in the study.

Only permanent teeth with fully formed crowns were scored for hypoplastic enamel defects. Permanent teeth that are not fully developed may not yield accurate results. If enamel was missing from the labial side of an anterior tooth or the buccal side of a molar, that tooth was not scored. In order to remain conservative and not score normal variation in perikymata as hypoplastic enamel defects, only those defects that could be seen with the naked eye were scored. All features that were suspected of being hypoplastic after initial examination with the naked eye were then confirmed with a 10X hand lens and fingernail palpation.

The LEH classification system as presented in Buikstra and Ubelaker (1994) was used to score the defects. However, due to small sample sizes, it was necessary to collapse the defects into two categories for statistical analysis, namely (a) grooves and (b) pits.

TABLE 2. Number of teeth available for scoring ${ }^{1}$

\begin{tabular}{lcccc}
\hline & Style 1 & Style 2 & Style 3 & Total \\
\hline Anterior teeth scored for hypoplastic defects & 36 & 37 & 88 & 161 \\
Posterior teeth scored for hypoplastic defects & 82 & 35 & 159 & 276 \\
Total scored for hypoplastic defects & 118 & 72 & 247 & 437 \\
& & & & \\
Anterior teeth scored for carious lesions & 35 & 35 & 89 & 159 \\
Posterior teeth scored for carious lesions & 83 & 35 & 156 & 274 \\
Total scored for carious lesions & 118 & 70 & 245 & 433 \\
\hline
\end{tabular}

${ }^{1}$ Style 1 refers to those burials with stone slabs and Mississippian pottery. Style 2 refers to those burials with stone slabs but no Mississippian pottery. Style 3 refers to those burials with no stone slabs or Mississippian pottery. 
Age is assigned based on the third of the crown on which the defect occurs. Lesions on the cervical-most third are most recent and those on the occlusal-most one-third are the earliest, with each third representing, in general, about 2 years (Schour and Massler, 1940; Massler et al., 1941). This system was used to place the defects into categories of 0-2 years, 2-4 years, 4-6 years, or 6 and over, depending on the developmental timing of the tooth.

All erupted permanent teeth were scored for the presence of carious lesions. Any tooth that was missing more than $1 / 4$ of the crown due to fracture was not scored. Carious lesions were scored according to standards presented by Buikstra and Ubelaker (1994). Due to small sample sizes, lesion location was collapsed into occlusal (including occlusal and smooth surface lesions, including buccal pits and grooves) and cervical (including cervical and interproximal lesions) categories for statistical analysis. Because the majority of the teeth in this sample consist of the crown only, root caries were not scored for any tooth. Carious lesions were confirmed using a 1OX hand lens. Rudney et al. (1983) suggest that visual identification is more reliable than dental probe or radiographic techniques. As suggested by Moore and Corbett (1971), only those lesions that have penetrated the surface enamel were scored.

Non-carious pulp exposure (attrition) was also recorded. While attrition is not a pathological condition, it was recorded in order to control for time since eruption of the tooth. Wear on molars was scored according to methods presented by Scott (1979). Teeth receive a score of four, being unworn to polished, to 40, having no remaining enamel. For this study, the median wear score of 11 was used to divide the teeth into categories of high wear and low wear. Wear on incisors, canines, and premolars was scored according to methods presented by Smith (1984). Teeth receive a score of 1 , being unworn to polished, to 8 , having no remaining enamel. The median wear score of three was used to divide teeth into categories of high wear and low wear.

The burial style categories used here include those burials that have stone slabs and Mississippian pottery (Style 1), those burials that have stone slabs but no pottery (Style 2), and those burials that have no stone slabs or pottery or (Style 3). Small sample sizes did not permit comparisons between each tooth type.

TABLE 3. Chi-square tests for presence of hypoplastic defects among burial styles ${ }^{1}$

\begin{tabular}{ccc}
\hline $\mathrm{n} \quad$ Chi-square & & \\
\hline Anterior teeth only & 161 & 6.74 \\
Posterior teeth only & 276 & 3.60 \\
\hline
\end{tabular}

${ }^{1}$ None was statistically significant.
Therefore, tooth types were collapsed into anterior (incisors, canines and premolars) and posterior (molars) categories. The number of teeth is approximately equal in most categories at the Ray site (Table 2). However, those burials with stone slabs but no pottery have a significantly greater number of incisors and fewer premolars within the anterior tooth category than the other burial styles. This may potentially bias the number of hypoplastic defects among the anterior teeth of this burial style.

Analysis of variance (ANOVA) was used to test differences in the numbers of hypoplastic defects and age of occurrence as well as the numbers of carious lesions per tooth between each of the three burial styles. The test examines the effects of the independent variables on the expression of hypoplastic defects or carious lesions (Kimble, 1978). All ANOVAs were run on SYSTAT for Windows version 6.0.1. In addition, to the parametric ANOVAs, nonparametric chi-square tests were used to test the differences in the number of teeth with at least one LEH or carious lesion as well as the types of LEHs and location of carious lesions. The chi-square tests are goodness-of-fit tests with two degrees of freedom (Thomas, 1986).

\section{RESULTS}

A total of 437 teeth were scored for hypoplastic defects. The burials with stone slabs and Mississippian pottery present (Style 1) contained 118 teeth (31\% of which have hypoplastic defects) while those with stone slabs but without Mississippian pottery (Style 2) contained 72 teeth $(46 \%$ of which have hypoplastic defects). Those burials with no stone slabs or Mississippian pottery (Style 3) contained 247 teeth (25\% of which have hypoplastic defects). There is an average of 0.85 defects per tooth in burial style 1, 1.03 defects per tooth in style 2 and 0.82 defects per tooth in style 3 . The overwhelming majority of defects in all groups are horizontal linear grooves with very few pits. The earliest age of onset for all groups has a peak frequency between 2 and 4 years.

A goodness-of-fit test suggests that there are no significant difference in frequency of affected posterior teeth between the burial styles (Table 3). However, burial style 2 has a greater proportion of anterior teeth with at least one hypoplastic defect than the other burial styles. Goodness-of-fit tests show no significant difference in the type of hypoplastic defect on the

TABLE 4. Chi-square statistic for LEH type among burial styles

\begin{tabular}{lll}
\hline $\mathrm{n} \quad$ Chi-square & & \\
\hline Anterior teeth only & 78 & $6.91^{*}$ \\
Posterior teeth only & 57 & 1.11 \\
\hline${ }^{*}<0.05$ & &
\end{tabular}


TABLE 5. Results of ANOVA for number of hypoplastic defects per tooth among burial styles ${ }^{1}$

\begin{tabular}{cccc}
\hline Source & $\mathrm{n}$ & $\mathrm{F}$ & $\mathrm{P}$ \\
\hline Anterior teeth only & 161 & 1.25 & 0.29 \\
Posterior teeth only & 276 & 1.56 & 0.21 \\
\hline
\end{tabular}

${ }^{1}$ None was significant statistically.

posterior teeth (Table 4). However, burial style 3 has a greater proportion of pits on the anterior teeth than the other burial styles. Significance for these tests and all other tests reported in this paper are based on an alpha of 0.05. ANOVA suggest no significant differences for the number of defects per tooth or earliest age at onset, regardless of tooth type. Table 5 summarizes the ANOVA results.

A total of 433 teeth were scored for carious lesions. Burial style 1 contains 118 teeth (29\% of which have carious lesions). Burials style 2 contains 70 teeth $(30 \%$ of which have carious lesions). Burial style 3 contains 245 teeth ( $28 \%$ of which have carious lesions). There is an average of 0.86 defects per tooth in burial style $1,0.90$ defects per tooth in burial style 2, and 0.85 defects per tooth in burial style 3. All groups have more occlusal than interproximal lesions.

Goodness-of-fit tests suggest that there are no significant difference between the burial styles regardless of tooth type or degree of wear (Tables 7 and 8). ANOVA suggests that no significant differences exist between the burial styles regardless of tooth type (Table 9).

\section{DISCUSSION}

Overall, hypoplastic defects are very similar among all burial styles represented at the Ray site. However, some differences were found. Burials with stone slabs but without Mississippian pottery (style 3 ) had a greater proportion of anterior teeth with hypoplastic defects than the other burial styles. However, those burials with stone slabs but without Mississippian pottery (style 2) had a substantially larger number of incisors and fewer premolars than the other burial styles. Because incisors are more likely to become hypoplastic, it is not surprising that the burial style with more incisors also has more defects.

TABLE 7. Results of Chi-square tests for presence of carious lesions among burial styles ${ }^{1}$

\begin{tabular}{lcc}
\hline & $\mathrm{n}$ & Chi-square \\
\hline Anterior teeth only & 159 & 1.04 \\
Posterior teeth only & 274 & 3.28 \\
High wear only & 185 & 0.55 \\
Low wear only & 248 & 1.00 \\
\hline
\end{tabular}

${ }^{1}$ None was significant statistically.
TABLE 6. Results of ANOVA for earliest age of occurrence for hypoplastic defects among burial styles ${ }^{1}$

\begin{tabular}{cccc}
\hline Source & $\mathrm{n}$ & $\mathrm{F}$ & $\mathrm{P}$ \\
\hline Anterior teeth only & 75 & 1.79 & 0.17 \\
Posterior teeth only & 51 & 0.08 & 0.92 \\
\hline
\end{tabular}

${ }^{1}$ None was significant statistically.

The mean number of hypoplastic defects per tooth does not vary significantly with burial style. This finding suggests that individuals from one burial style did not undergo a greater number of stresses during the time of development than the other burial styles.

The earliest age at onset of hypoplastic defects does not vary significantly with burial style. Some may argue that given the broad age ranges used, this would reflect the tendency of hypoplastic defects to form on the middle thirds of the crowns (i.e., the age range 2-4 tends to fall the middle third for most teeth). However, the distribution for all age ranges was similar among the burial styles. All burial styles had a peak frequency in the 2-4 year category with the second highest occurrence in the 4-6 year category and the lowest occurrence in the 0-2 year category. This distributions suggest that within each age category, individuals from all burial styles were equally susceptible to hypoplastic defect formation.

The type of hypoplastic defect does vary significantly with burial style. Burial style 3 has a significantly greater number of pits on the anterior teeth than do the other burial styles. All pits from this burial style are found in a single burial. Therefore, the greater number of pits is only representative of one burial, not the burial style as a whole. The pits are also from a minimum of two individuals. Therefore, the sample may be biased by a few individuals. It has been suggested that different types of hypoplastic defects (grooves vs. pits) may have different etiologies in some populations (Lovell and Whyte, 1999). However, there is no evidence in the literature to substantiate this claim. Thus the nominal differences seen in hypoplastic defect frequency are most likely biased and to not suggest the presence of two populations at the Ray site.

Comparisons with other sites from known time

TABLE 8. Chi-square tests for location of carious lesions among burial styles ${ }^{1}$

\begin{tabular}{lrc}
\hline & $\mathrm{n}$ & Chi-square \\
\hline Anterior teeth only & 13 & 1.64 \\
Posterior teeth only & 115 & 4.39 \\
High wear only & 64 & 3.91 \\
Low wear only & 62 & 2.07 \\
\hline
\end{tabular}

${ }^{1}$ None was significant statistically. 
TABLE 9. Results of two-way ANOVA for number of carious lesions per tooth among burial styles ${ }^{1}$

\begin{tabular}{lccc}
\hline \multicolumn{1}{c}{ Source } & $\mathrm{n}$ & $\mathrm{F}$ & $\mathrm{P}$ \\
\hline Anterior teeth only & & & \\
$\quad$ Burial Style & 159 & 0.52 & 0.60 \\
$\quad$ Wear & 159 & 0.06 & 0.81 \\
$\quad$ Style-x-Wear & 159 & 1.55 & 0.21 \\
$\quad$ & & & \\
Posterior teeth only & & & \\
$\quad$ Burial Style & 274 & 2.09 & 0.13 \\
$\quad$ Wear & 274 & 0.26 & 0.61 \\
$\quad$ Style-x-Wear & 274 & 1.10 & 0.33 \\
\hline
\end{tabular}

${ }^{1}$ None was significant statistically.

periods are difficult because most data are given per individual and most teeth from the Ray site mortuary could not be reassociated. Peak frequencies for age of onset provided for both the Late Woodland (3.0-3.5 years) and the Mississippian (2.5-3.0 years) groups at the Dickson Mounds (Goodman et al., 1984a) are given in half-year age ranges and both fall into the 2-4 year category used in this study.

The frequency and expression of carious lesions was very similar for each burial style. The proportion of teeth with at least one carious lesion does not vary significantly based on burial style, regardless of tooth type or degree of wear. The mean number of lesions per tooth does not vary significantly based on burial style, regardless of tooth type or degree of wear. This would suggest that there are no factors, either dietary (e.g., amount of carbohydrates consumed) or biological (e.g., differences in saliva flow or $\mathrm{pH}$ ) that make the teeth of any one burial style more susceptible to caries. The location of carious lesions does not differ significantly based on burial style, regardless of tooth type or degree of wear. This would suggest that the diets of individuals from each burial style were equally cariogenic.

The frequency and expression of carious lesions at the Ray site are consistent with other known Mississippian period populations. The number of carious lesions per anterior tooth at the Ray site is nearly identical to that listed for the Kane Mounds, a Mississippian period site in Illinois (Milner, 1984). The number of lesions per posterior tooth is also very similar, the only difference occurring when the category is divided into specific tooth types. The second molars of Milner's (1984) sample appear to have a greater number of lesions per tooth than those from the Ray site, however this may be due to smaller sample sizes for this tooth at the Ray site. Thirty-six percent of the posterior teeth of the Kane Mounds groups have occlusal carious lesions. After correcting for Milner's (1984) scoring method, 33\% of the posterior teeth from the Ray site have occlusal carious lesions.

It appears that all individuals from the Ray site mortuary were from the same temporal and social group. The high degree of processing of the remains, the commingled nature of the remains, and the elaborate nature of some of the graves (i.e., stone slabs) suggest that the Ray site mortuary contained individuals of higher social status (Goldstein, 1980). Because there are more stages in processing the higherstatus burials, primary and secondary interments are usually present (Goldstein, 1980). It is likely that the different burial styles at the Ray site represent different stages in processing the remains of individuals from the same temporal/social group rather than distinct subgroups. Because there is no difference in frequency or expression of hypoplastic defects or carious lesions between the burial styles, and the carious lesion data for this site are not inconsistent with known Mississippian mortuaries, this study would suggest that all burial styles present at the Ray site are indeed associated with the Mississippian period.

\section{SUMMARY AND CONCLUSIONS}

The purpose of this study was to assess, via an analysis of dental pathological conditions, the biological homogeneity of a small Mississippian mortuary with differing burial styles. Despite burial heterogeneity, there is no evidence among the dental pathological conditions studied to suggest that more than one population is present in the Ray site mortuary. The frequency and expression of hypoplastic defects suggests individuals all burial styles underwent similar childhood stresses. The frequency and expression of carious lesions also suggest that individuals from all burials consumed an equally cariogenic diet. The different burial styles present at the Ray site most likely represent different stages in the processing of remains consistent with high social status Mississippian mortuaries. Future studies should attempt to compare the dental pathological conditions at the Ray site with those of other small Mississippian high and low status mortuaries in the Midwest.

\section{ACKNOWLEDGEMENTS}

The Ray site skeletal material is on loan to the University of Indianapolis, Archeology and Forensics Laboratory from the Indiana University, Glenn Black Laboratory. I would like to thank Stephen Ball of the Glenn Black Laboratory and Christopher Schmidt of the University of Indianapolis for access to the skeletal material.

\section{LITERATURE CITED}

Ball S. 1993. The Ray site: Early Angel phase mortuary behavior. Paper presented at the Midwest Archaeological Conference.

Bang G, Kristoffersen T. 1972. Dental caries and diet in an Alaskan Eskimo population. Scand J Dent Res 80: 440-444. 
Black GA. In Press. The Yankeetown complex with special reference to the Ray site -W6. Unpublished manuscript on file at the Glenn Black Laboratory, Indiana University, Bloomington, Indiana.

Buikstra JE. 1992. Diet and disease in late prehistory. In: Verano JW, Ubelaker DH, editors. Disease and demography in the Americas. Washington: Smithsonian Institution Press, p 87-101.

Buikstra JE, Ubelaker DH. 1994. Standards for data collection from human skeletal remains. Arkansas archaeological survey research series No. 44 .

Corbett ME, Moore WJ. 1976. Distribution of dental caries in ancient British populations. Caries Res 10: 401-414.

Enwonwu CO. 1981. Review of oral disease in Africa and the influence of socio-economic factors. Int Dent J 31:29-38.

Gibbons RJ, van Houte J. 1975. Dental Caries. Annual Review of Medicine: Selected topics in clinical sciences. 26:121-136

Goldstein LG. 1980. Mississippian mortuary practices: A case study of two cemeteries in the lower Illinois valley. Evanston, Illinois: Northwestern University Archeological Program.

Goodman AH, Armelagos GJ. 1985. Factors affecting the distribution of enamel hypoplasias within the human permanent dentition. Am J Phys Anthropol 68:479-493.

Goodman AH, Armelagos GJ, Rose JC. 1984a. Chronological distribution enamel hypoplasias from prehistoric Dickson Mounds populations. Am J Phys Anthropol 65:259-266.

Goodman AH, Lallo J, Armelagos GJ, Rose JC. 1984b. Health changes at Dickson Mounds, Illinois (A.D. 950-1300). In: Cohen MN, Armelagos GJ, editors. Paleopathology at the origins of agriculture. Orlando: Academic Press, Inc. p 271-305.

Goodman AH, Rose JC. 1990. Assessment of systemic physiological perturbations from dental enamel hypoplasias and associated histological structures. Yearbook Phys Anthropol 33:59-110.

Goodman AH, Rose JC. 1991. Dental enamel hypoplasias as indicators of nutritional status. In: Kelly MA, Larsen CS, editors. Advances in dental anthropology. New York: Wiley-Liss. p 279-293.

Heloe LA, Haugejorden 0. 1981. The rise and fall of dental caries: some global aspects of dental caries epidemiology. Oral Epidem 9:294-299.

Hillson SW. 1979. Diet and dental disease. World Archeol 11:147-162.

Infirri JS, Barmes DE. 1979. Epidemiology of oral diseases: differences in national problems. Int Dent J 29:183-190.

Jacobsen J, Hansen ER. 1974. Cariessituationen I Gronland 1973/74. Tandlaegebladet 78:839-847.

Kelley MA, Levesque DR, Weidl B. 1991. Contrasting patterns of dental disease in five early northern
Chilean groups. In: Kelley MA, Larsen CS, editors. Advances in Dental Anthropology. New York: Wiley-Liss. p 203-213.

Kimble GA. 1978. How to use and misuse statistics. Englewood Cliffs, New Jersey: Prentice-Hall, Inc.

Larsen CS. 1995. Bioarchaeology: Interpreting behavior from the human skeleton. Cambridge, United Kingdom: Cambridge University Press.

Larsen CS, Shavit R, Griffin MC. 1991. Dental caries evidence for dietary change: an archaeological context. In: Kelley MA, Larsen CS, editors. Advances in Dental Anthropology. New York: Wiley-Liss. p 179-202.

Lukacs JR. 1996. Sex differences in dental caries rates with the origin of agriculture in south Asia. Curr Anthrop 37:147-153.

Massler M, Schour I, Poncher HG. 1941. Developmental pattern of the child as reflected in the calcification pattern of the teeth. Am J Dis Child 62:33-67.

Mayhall JT. 1970. Effect of culture change upon the Eskimo dentition. Arctic Anthrop 7:117-121.

Milner GR. 1984. Dental caries in the permanent dentition of a Mississippian period population from the American Midwest. Coll Antropol 1:77-91.

Moore WJ, Corbett ME. 1971. The distribution of dental caries in ancient British populations. Caries Res 5: 151-168.

Pedersen P0. 1938. Meddelelser om odontologiske undersogelser pa Grønland. Tandlaegebladet 42: 127-157.

Pindborg JJ. 1970. Pathology of dental hard tissue. Philadelphia: WB Saunders Company.

Powell ML. 1985. The analysis of dental wear and caries for dietary reconstruction. In: Gilbert Jr. RI, Mielke JH, editors. The analysis of prehistoric diets. Orlando: Academic Press, p 307-338.

Rudney JD, Katz RV, Brand JW. 1983. Interobserver reliability of methods for paleopathological diagnosis of dental caries. Am J Phys Anthropol 62: 243-248.

Schmidt CW. 1998. Dietary reconstruction among prehistoric humans from Indiana: an analysis of dental macrowear, dental pathology, and dental microwear. Ph.D. dissertation, Purdue University.

Schmidt CW, Williamson MA. 1998. Paleopathology at the Late Woodland Albee Phase, Commissary Site (12Hn2): Implications for sedentism and maize consumption. Indiana Arch 2:43-69.

Schour I, Massler M. 1940. Studies in tooth development: The growth pattern of human teeth II. J Am Dent Assoc 27:1918-1931.

Sciulli PW. 1978. Developmental abnormalities of the permanent dentition in prehistoric Ohio Valley Amerindians. Am J Phys Anthropol 48:193-198.

Sciulli PW, Schneider KN. 1986. Dental caries and horticulture in prehistoric Ohio. Penn Arch 56:2128. 
Scott EC. 1979. Dental wear scoring technique. Am J Phys Anthropol 51:213-218.

Smith BH. 1984. Patterns of molar wear in huntergatherers and agriculturalists. Am J Phys Anthropol 63:39-56.

Smith MO. 1986. Caries frequency and distribution in the Dallas skeletal remains from Toqua (40MR6), Monroe County, Tennessee. Tennessee Anthropol 11:145-155.

Thomas DH. 1986. Refiguring anthropology: first principles of probability and statistics. Prospect Height, Illinois: Waveland Press, Inc.

Walker PL, Erlandson J. 1986. Dental evidence for prehistoric dietary change on the northern Channel Islands. Am Antiq 51:375-383.

\section{Spread the Word}

Have you developed a web-site relevant to dental anthropology? Please let us know if have webbased information about dental anatomy, forensic dentistry, dental trait variation, a novel statistical approach - or almost anything else relevant to the readers of Dental Anthropology. Let us know, and we'll publicize the site. Send the location of the site and supply a short description of its purpose and content. E-mail your information to the Editor: eharris@utmem.edu. 